\title{
Immobility responses in Anolis carolinensis
}

\author{
DANIEL G. WEBSTER, THOMAS H. LANTHORN, and MERLE E. MEYER \\ University of Florida, Gainesville, Florida 32611
}

\begin{abstract}
A"retrieval-like" response, similar to that exhibited by the young of many mammalian species when carried by adults, was found to be exhibited by Anolis carolinensis. These animals were found to be more susceptible to induction of this inhibitory response than to tonic immobility. The results are discussed in terms of possible common neural mechanisms mediating these complex behavioral inhibitory states.
\end{abstract}

A variety of species are known to exhibit various complex states of behavioral inhibition and immobility in response to certain types of stimulation (i.e., Gallup, 1974; Lefebvre \& Sabourin, 1977). Two of the major characteristics shared by these states are a tonic rigidity, generally involving a particular posture, and a greatly reduced responsiveness to external stimuli. The most commonly studied of these responses is tonic immobility, which is generally induced by inverting an animal on its back and restraining it for a short period. Another of these behavioral inhibitory states is the "retrieval response," exhibited by the young of many mammalian species when the adults lift and carry them by the skin at the scruff of the neck. Recent investigations (Webster, Lanthorn, Dewsbury, \& Meyer, Note 1) have demonstrated that this response is also exhibited by adult animals from a wide range of muriod rodent species.

The present study was conducted to gain a better understanding of the generality of this "retrievallike response" and its relation to tonic immobility, and, in particular, to determine if this response could be reliably induced in a species which does not exhibit retrieval of the young. It has long been known that tonic immobility may be readily and reliably induced in Anolis carolinensis (e.g., Hoagland, 1928), and recent studies have demonstrated that susceptibility to and duration of tonic immobility in this species is affected by many of the same factors which affect this state in other species, including various mammalian species (i.e., Edson \& Gallup, 1972; Gallup, 1973; McKnight, Copperberg, \& Ginter, 1978). For these reasons, Anolis carolinensis appeared to be a good choice for the present study.

\section{METHOD}

Subjects for this study were eight mature Anolis carolinensis obtained through Carolina Biological Supply. The animals were housed in a $61 \times 31 \times 41 \mathrm{~cm}$ aquarium with a hardware cloth cover. The bottom of the aquarium was covered with $3 \mathrm{~cm}$ of wood shavings, and an inverted $v$-shaped piece of hardware cloth

The authors would like to thank Donald A. Dewsbury for contributing the figures for this manuscript. was provided for the animals to climb on. Fresh water and mealworms were provided each afternoon, and cockroaches were supplied twice a week. The animals were maintained on a 10:14 photoperiod for 2 weeks prior to testing and were disturbed only for feeding.

The animals were tested in the last half of the light portion of their light-dark cycle. In order to speed handling and make identification of individuals simpler, all animals were placed in separate, small $(29 \times 18 \times 13 \mathrm{~cm})$ plastic cages with wire-mesh tops immediately prior to testing. All animals were tested in an aquarium in order to prevent escape. The animals were placed in the test aquarium $30 \mathrm{sec}$ prior to testing. During testing, one experimenter handled the animals while the other timed the duration of the response. Half the animals were tested first for tonic immobility, and the other half were tested first for the "retrieval-like response," with all animals receiving three trials under each condition and $1 \mathrm{~h}$ between the two types of tests.

Tonic immobility tests were conducted by restraining the animals on their backs in an $18 \times 9 \times 3.5 \mathrm{~cm}$ v-shaped trough, with one finger placed at the base of the tail and another at the base of the jaw. A slight pressure was maintained until either the animal had stopped struggling or $10 \mathrm{sec}$ had elapsed. If the animal stopped struggling, the experimenter's hand was lifted and response duration was timed from this point until the animal righted itself or until a maximum of $300 \mathrm{sec}$ had elaspsed (see Figure 1). Animals that displayed the response for $300 \mathrm{sec}$ were tapped gently by the experimenter to terminate the response. After termination of the response, the animal was allowed to sit in the trough for $15 \mathrm{sec}$ before the next trial was begun.

Retrieval-like response trials were conducted by lifting the animal off its feet by the skin at the back of the neck. Retrieval-like response duration was scored from the time the animal stopped struggling and assumed a rigid posture (see Figure 2) until the animal began to struggle again or $300 \mathrm{sec}$ had passed, whichever came first. As soon as a trial ended, the subject was placed back in the aquarium and allowed to remain there for $15 \mathrm{sec}$, at which time the next trial was begun. Trials on which the subject did not cease struggling within $10 \mathrm{sec}$ were counted as no-response trials.

\section{RESULTS}

The retrieval-like response was observed on a significantly greater number of trials $(p<.05$; Wilcoxon test) than was tonic immobility. While the retrievallike response was exhibited by every subject on all trials, tonic immobility, although exhibited by all subjects, was not exhibited on every trial (see Table 1).

Animals exhibited the retrieval-like response for significantly longer durations than they did tonic immobility, whether considering just positive trials 
$(p<.01)$ or the average of all three trials $(p<.001)$ in a paired t test comparison. The durations of the retrieval-like response and tonic immobility were not found to be correlated with the number of trials on which these responses were exhibited, nor were the durations of these two responses found to be correlated with each other. Order of presentation of the two conditions produced no significant effects $[\mathrm{F}(1,6)=1.42, \mathrm{p}=.279]$.

\section{DISCUSSION}

The results clearly demonstrate that a retrievallike response may be reliably induced in Anolis using the same method of induction effective in inducing this state in mammals. Not only could this state be readily induced in this species, but they were actually more susceptible to the retrieval-like response than to tonic immobility. This parallels results we have found with rodents. The retrieval response, as exhibited by young mammals, is often thought to be adaptive because it limits struggling while the young are being carried by the mother. However, since the response may be reliably elicited in a species in which the young are not retrieved, as well as in adult rodents (Webster, Lanthorn, Dewsbury, \&

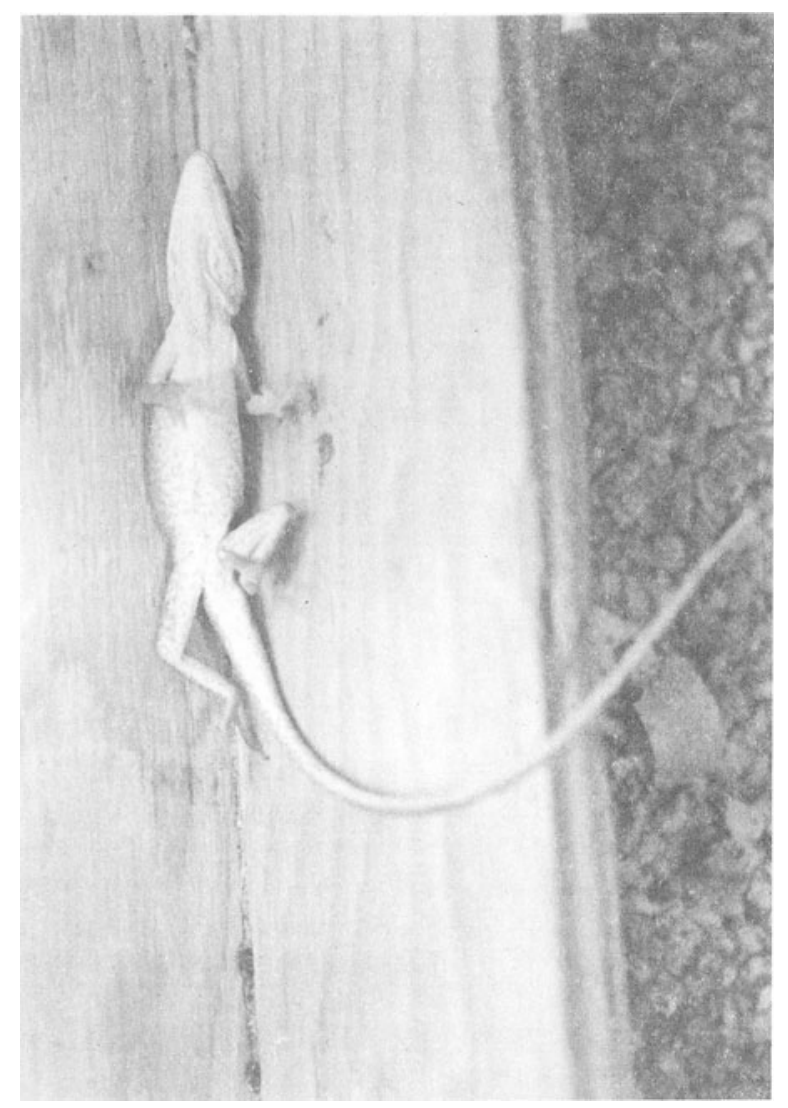

Figure 1. Anolis carolinensis displaying the tonic immobility response.

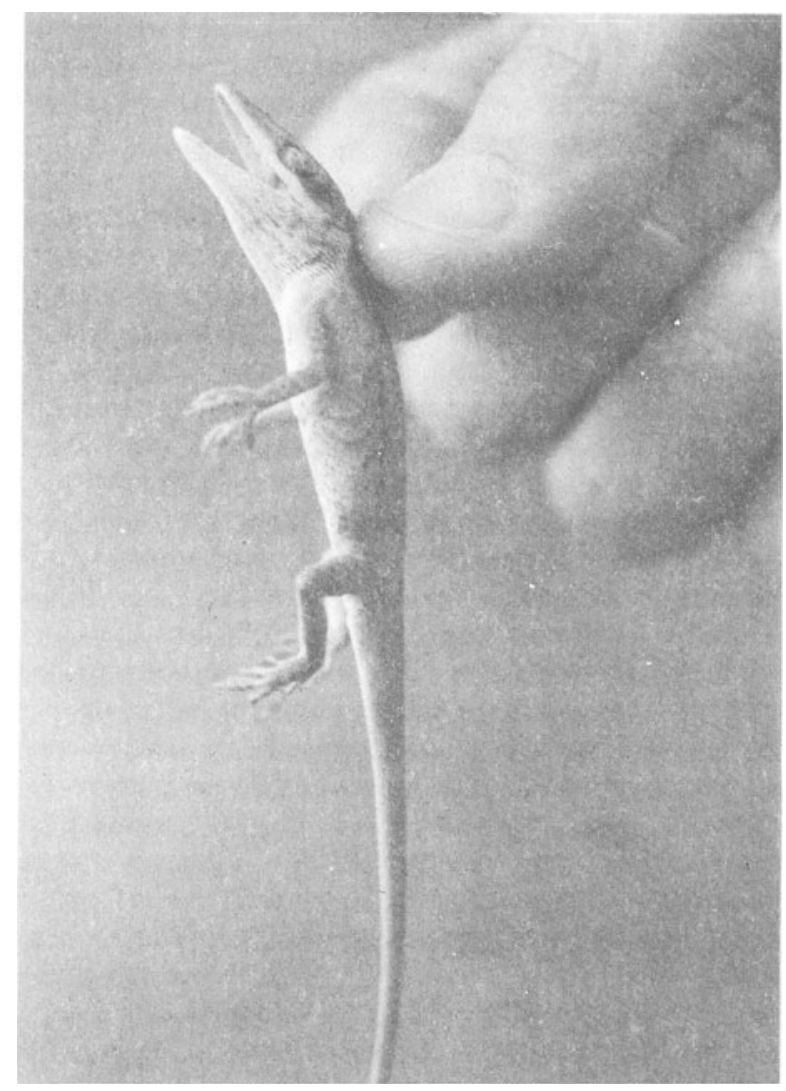

Figure 2. The retrieval-like response.

Meyer, Note 1), it is apparent that the response did not evolve in this context.

The retrieval-like response has in common with many other immobility responses the fact that it is induced by restraining the animal. In unsystematic observations carried out at the conclusion of this experiment, it was found that an immobility state could also be induced in Anolis through a manipulation similar to one which is effective in inducing immobility in chickens. In this manipulation, the animal is placed on its stomach, the front legs tucked back toward

Table 1

Average Duration of Positive Trials (in Seconds)

\begin{tabular}{|c|c|c|c|c|}
\hline \multirow[b]{3}{*}{ Subject } & \multirow{2}{*}{\multicolumn{2}{|c|}{$\begin{array}{c}\begin{array}{c}\text { Tonic Immobility } \\
\text { Response }\end{array} \\
\text { Positive Trials }\end{array}$}} & \multirow{2}{*}{\multicolumn{2}{|c|}{$\frac{\begin{array}{c}\text { Retrieval-Like } \\
\text { Response }\end{array}}{\text { Positive Trials }}$}} \\
\hline & & & & \\
\hline & Duration & Number & Duration & Number \\
\hline 1 & 300.00 & 1 & 300.00 & 3 \\
\hline 2 & 137.00 & 2 & 272.00 & 3 \\
\hline 3 & 46.00 & 2 & 240.30 & 3 \\
\hline 4 & 300.00 & 2 & 300.00 & 3 \\
\hline 5 & 141.50 & 2 & 225.67 & 3 \\
\hline 6 & 167.30 & 3 & 190.67 & 3 \\
\hline 7 & 68.65 & 3 & 186.67 & 3 \\
\hline 8 & 46.50 & 2 & 107.00 & 3 \\
\hline
\end{tabular}




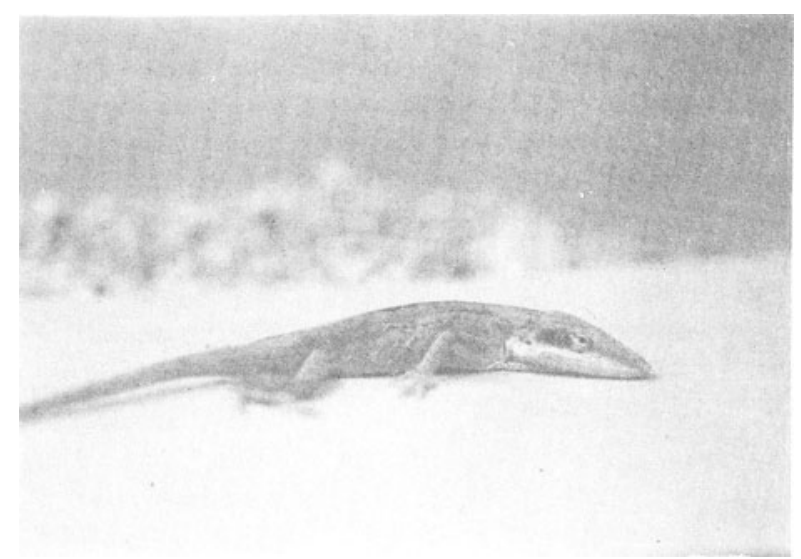

Figure 3. A behavioral inhibitory response induced in Anolis through manipulations similar to those commonly used to induce tonic immobility in chickens.

the tail, and the neck and shoulders pressed to the substrate (see Figure 3)

The similarity of procedures effective in producing immobility responses in a wide range of species suggests that a common response mechanism may be mediating these complex behavioral-inhibitory states, irrespective of the present apparent adaptive value of any particular immobility response in a particular species.

The common denominator in most experimental situations designed to induce these complex behavioral inhibitory reflexes is some type of physical restraint which results in pressure on the sensory fields of the head, neck and trunk regions of the animal's body. In general, it appears that these behavioral inhibitory reflexes are obtained by the stimulation of the sensory fields of the Vth, IXth, and Xth cranial nerves and are mediated by the baroreceptor reflex (Hatton, Lanthorn, Webster, \& Meyer, 1978; Hatton, Webster, Lanthorn, \& Meyer, 1979). Thus, these behavioral inhibitory reflexes appear to be common to other reflexes, such as the J-reflex (Ahluwalia, Langhurst,
Krienke, \& Koepchen, 1977), the bandaged head backfall reflex (Teitelbaum, Wolgin, De Ryck, \& Marin, 1976), and other depressor reflexes obtained by stimulation of the same sensory fields of the $\mathrm{Vth}$, IXth, and Xth cranial nerves.

\section{REFERENCE NOTE}

1. Webster, D. G., Lanthorn, T. H., \& Dewsbury, D. A. Tonic immobility and retrieval-like responses in 12 species of muroid rodents. Manuscript in preparation.

\section{REFERENCES}

Ahluwalia, J. S., Langhurst, P., Krienke, B., \& Koepchen, H. P. Nucleus of the solitary tract and the J-reflex. Pflügers Archiv, 1977, 368, 157-159.

Edson, P. H., \& Gallup, G. G., JR. Tonic immobility as a fear response in lizards (Anolis carolinensis). Psychonomic Science, 1972, 26, 27-28.

Gallup, G. G., Jr. Simulated predation and tonic immobility in lizards (Anolis carolinensis). Copeia, 1973, 3, 623-624.

Gallup, G. G., JR. Animal hypnosis: Factual status of a fictional concept. Psychological Bulletin, 1974, 81, 836-853.

Hatton, D. C., Lanthorn, T., Webster, D. G., \& Meyer, M. E. Baroreceptor involvement in the immobility reflex. Behavioral Biology, 1978, 22, 122-127.

Hatton, D. C., Webster, D. G., Lanthorn, T., \& Meyer, M. E. Evidence for baroreceptor involvement in the immobility reflex in the rabbit: Blood pressure changes during induction and termination. Behavioral and Neural Biology, 1979, 26, 89-94.

Hoagland, H. On the mechanism of tonic immobility in vertebrates. Journal of General Physiology, 1928, 11, 715-741.

Lefebvre, L., \& Sabourine, M. Response differences in animal hypnosis: A hypothesis. Psychological Record, 1977, 27, 77-87.

McKnight, R. R., Copperberg, G. F., \& Ginter, E. J. Duration of tonic immobility in lizards (Anolis carolinensis) as a function of repeated immobilization, frequent handling and laboratory maintenance. Psychological Record, 1978, 28, 549-556.

Teitelbaum, P., Wolgin, D. L., De Ryck, M., \& Marin, O. Bandage-backfall reaction: Occurs in infancy, hypothalamic damage and catalepsy. Proceedings of the National Academy of Science, 1976, 73, 3311-3314.

(Received for publication July 19, 1979; revision accepted September 11, 1979.) 